\title{
Meeting the social support needs of older rural people in Central Otago: The impact of a pilot social work position
}

\author{
Sharnee Diamond and Chrystal Jaye \\ University of Otago, Aotearoa New Zealand
}

\begin{abstract}
INTRODUCTION: This project aimed to identify the support needs of older people living in rural Central Otago, Aotearoa New Zealand and to ascertain if a pilot social work position was meeting these needs.

METHODS: Data were collected during December 2019. Twelve semi-structured qualitative interviews were conducted with the social worker, referrers of the social worker's clients, key community stakeholders, and the older rural residents supported by the social worker.
\end{abstract}

FINDINGS: An interpretive analysis of the data identified two key thematics: 1) being older in Central Otago; and 2) providing aged social work services in this region.

CONCLUSION: Despite the positive impact that the Age Concern Otago social work position is having for clients of the service, the need for social support for older rural people in Central Otago continues to grow. In addition to increasing social worker resourcing, better coordination and linking between the government and non-government agencies operating in this space would improve the effectiveness of aged social work services, as would improved visibility of these services within the community.

KEYWORDS: Social work; rural health; older people; ageing in place

AOTEAROA

NEW ZEALAND SOCIAL WORK 32(4), 116-130.

CORRESPONDENCE TO: Chrystal Jaye

chrystal.jaye@otago.ac.nz
This article reports on a modest qualitative study exploring a pilot social work position in Central Otago that was established to support older people in the region. The rural context of providing social support to older people is unique both in the issues that older rural people commonly experience, and in the scope of social work practice (Smith, 2013). Our findings reflect those of a growing body of work identifying and investigating forms of precarity in ageing-both from the experience of older adults and those who support them (Grenier, Phillipson, \& Settersten, 2020). Precarity has been defined in the Aotearoa New Zealand context as a form of vulnerability that is characterised by powerlessness, insecurity, uncertainty and perilousness (Groot, van Ommen, MastersAwatere, \& Tassell-Matamua, 2017).

There is no one accepted definition of rurality in Aotearoa New Zealand which makes it difficult to provide accurate estimates of the rural population (Fearnley, Lawrenson, \& Nixon, 2016). It has been estimated that the rural population of Aotearoa New Zealand numbers approximately 620,000 people (Pittaway, 2017). Pittaway (2017) noted that if 
this population was clustered in one location, it would be equivalent to the second largest city in Aotearoa New Zealand (Pittaway, 2017). Data from the Aotearoa New Zealand 2018 Census indicates that around 16.2\% of the rural population is over 65 years (compared to $15.5 \%$ of the total population) while $9.5 \%$ of the rural population is older than 80 years (compared to $3.5 \%$ of the total population) (Statistics New Zealand, 2020a). These figures mirror international data indicating that older people are overrepresented in rural populations (Keating \& Phillips, 2008; Malatsky \& Bourke, 2016). Like other nations (Keating \& Phillips, 2008), it is likely that the proportion of older people in the Aotearoa New Zealand rural population is increasing at a more rapid rate than in urban areas (Pomeroy \& Newell, 2011).

Aotearoa New Zealand currently supports the principle of ageing in place for older people (Ministry of Health, 2001, 2011; Office for Seniors, 2019). An Aotearoa New Zealand review of what ageing in place meant to older rural residents revealed that ageing within their familiar rural community provided a sense of continuity and identity (Wiles, Leibing, Guberman, Reeve, \& Allen, 2012). The success of ageing in place in a rural context is dependent on the availability of, and access to, health and social services (Keating \& Phillips, 2008). Despite initiatives such as "Live Stronger for Longer" that aim to support older people (in this case combining a focus on fall reduction with a positive ageing message for older people and organisations), support is unevenly distributed and can be difficult to access for those living in rural areas (National Health Committee, 2010; Parr \& Philo, 2003; Pittaway, 2017; Rural Expert Advisory Group, 2002).

Previous research indicated disparities between rural and urban access to health services within Aotearoa New Zealand (Lilburn, 2016) and in the Otago region specifically (Nixon et al., 2014; Smith, Humphreys, \& Wilson, 2008). Longer travel times to primary health services have been associated with lower service utilisation in rural areas (Hiscock, Pearce, Blakely, \& Witten, 2008), and the geographical barriers associated with ruralism can exacerbate the inevitable difficulties that come with ageing. These include barriers of isolation, loneliness, transportation, and limited mobility (Chalmers \& Joseph, 1998; Lilburn, 2016). Health and social services delivered directly to the homes of older people have been recently presented as the most effective approach for support for older rural residents (Ergler et al., 2017), as this eliminates the need for older individuals to travel and incur associated expenses.

Howard-Brown (2018) has suggested that Aotearoa New Zealand has a substantial disconnect between the stated government commitment to supporting those ageing in rural communities, and the support provided to the agencies engaged in meeting the needs of older rural people. One focus of the 2001 "Positive Ageing Strategy" was to ensure that older rural residents were not disadvantaged with regard to access to health care services (Ministry of Health, 2001). While the more recent "Healthy Ageing Strategy" (Associate Minister of Health, 2016) does not refer specifically to older people in rural contexts, its vision is that older people live well and age in place within aged-friendly communities. As Davey (2006) notes, ageing in place is favoured within policy on older people, and refers to the social and wellbeing benefits associated with older people remaining in their own homes and communities. Evaluations conducted in urban settings indicated that well co-ordinated, home-based packages can successfully support ageing in place (Parsons et al., 2012; Wiles et al., 2012).

Malatsky and Bourke (2016) suggested that, if these unique challenges are to be successfully met, rural health has to be understood within its own contexts. While rural communities are often characterised as being close-knit supportive environments, older adults who have decreased social capital (Keating \& Phillips, 2008), chronic 
health issues, and/or financial hardship are particularly vulnerable to the loss of social support and marginalisation (Wenger \& Keating, 2008). Scharf and Bartlam (2008) noted that rural poverty can be dispersed and hidden, and just as in urban regions, rural older people can be subject to social exclusion. Additionally, social networks are not the same as support networks, and may not provide the tangible, emotional or functional support that older people require to age successfully in place (Wenger \& Keating, 2008). Assumptions that community networks can compensate for the lack of rural services can disadvantage older rural people (Keating \& Phillips, 2008).

The present research project was conducted by University of Otago researchers affiliated to the CARE Research Theme in collaboration with the Otago regional branch of a national non-government organisation (NGO) dedicated to the welfare of older adults in New Zealand, Age Concern Otago (ACO). In 2019, ACO established a 12-month, 0.5 full time equivalent (FTE), fixed-term social worker position in Central Otago to support older residents living independently (not in aged residential care) in the region. This position was established in response to evidence of a need in the region for a specialist social worker for older people over and above an existing Elder Abuse Response position. This NGO's need to understand the impact of this position provided the inspiration for this project. When this position was established, the role description for this position was deliberately written to be broad. ACO's intention was that the organisation would develop a role description for the permanent position based on the needs of the target population which would become apparent during the fixed term of the pilot position. In order to understand whether the ACO social work position was meeting the needs of older rural people in this area, we also needed to understand what those needs were. Therefore, the aims of this project were to: 1) identify the support needs of the older rural people living in rural Central Otago; and 2) evaluate if these needs were being met by the ACO pilot social work position located in Central Otago. These findings were intended to inform ACO's decision regarding the continuation of its social worker position in this region.

The ACO social work position created in 2019 carries the official title of Central Service Co-ordinator (CSC) and is physically located in Alexandra, a small town of 3000 people and the hub for the Central Otago District Council and local business. The principal objective of the Central Service Coordinator role is to provide information and support to older people, their families and carers, and promote choice, independence, empowerment, safety, wellbeing and social participation. It also involves liaising with other services as appropriate. The majority of ACO clients in Central Otago are referred to the CSC by other agencies, particularly health professionals in the region but also by churches and the local ACO Elder Abuse Response social worker.

The region within the Central Otago jurisdiction lies in the lower South Island. It covers approximately 10,000 square kilometres and hosts a population of around 22,000 (Statistics New Zealand, 2020b). Rapid growth combined with inward migration by retirees and life-stylers has seen the population increase by around $40 \%$ in the previous 14 years. The percentage of the population over 65 years of age mirrors the national rural estimates for Aotearoa New Zealand. In Central Otago, $16 \%$ of the population is over 65 , and $9.5 \%$ is over 80 years of age, while approximately $8 \%$ are Māori (Statistics New Zealand, 2020b). In addition to pharmacy, dental, optometry, audiology, physiotherapy and occupational services, Alexandra has two general practices and a small hospital with a 24-bed, in-patient acute ward that serves the Central Otago region.

\section{Method}

The first author conducted this project for a summer studentship over a 10-week period. 
The study is situated within a pragmatic and interpretive theoretical approach (Kazi, 2000; Morgan, 2007; Schwandt, 1998) that reflected the real-world focus of the project (Anastas, 2004). As Anastas (2004) noted, qualitative research designs are particularly useful in understanding the needs of community members, client and stakeholders' perceptions of a service, outcomes, possible improvements and gaps in services and interventions.

The research design incorporated both interviews and observation (Braun \& Clarke, 2013; Dobl, Beddoe, \& Huggard, 2017; Dobl \& Ross, 2013). The first author conducted interviews with community members who were clients of the CSC, with referrers to the ACO service, with the CSC, and with other key stakeholders in the community. She also spent a day observing the CSC at work while she visited her clients and met with other key support professionals in Central Otago. This approach provided a degree of methodological triangulation in several ways (Flick, 2018). It established that the CSC's assessment of client need in her jurisdiction, and of the issues faced by social workers were consistent with that of social workers based in other rural centres in the region. The observational data provided a context for the challenges facing older rural people who are struggling to remain independent. Client interviews supported key informant interview data with first-hand descriptions of what support they needed in order to remain independent.

\section{Sampling and recruitment}

The sample consisted of 12 participants (including the CSC): six older individuals (ranging from 70-95 years of age) living in Central Otago, and six key informants (comprising four other social workers in Central Otago referred to as social worker A, $B, C$, and D respectively, one senior member of the local district council, and one former social worker (E). We do not provide further detail on the four key informant social workers in our sample in order to avoid compromising their anonymity apart from noting that mental health and elder abuse are among their areas of expertise. We are unable to anonymise the CSC. While this sample size is modest, it was appropriate for the timeframe and the intensive work required for the study (Anderson, 2010). The client recruitment strategy was guided by the CSC who identified potential participants from her current caseload in the Central Otago region. Potential key informants were identified and recruited by the first author using government service websites and the professional networks of Age Concern Otago. In the 2-3 week period prior to fieldwork, project consent forms were distributed by the CSC. On the day of the interview, verbal consent for participation in the project was also obtained.

Although the sample was modest, client participants were purposively selected to illustrate the range of the CSC's caseload (see Table 1). This combination of purposive and convenience sampling illustrated, not only the varied cases which a CSC will support at any one time, but also provides a reliable indication of the different experiences of ageing in a rural community. The selection guidance by the CSC could be viewed as a conflict of interest. However, this recruitment strategy was pragmatic in light of the overarching aim and objectives of the project, and its dependence upon the CSC's clientele. Despite the potential for bias, it appeared to be the only avenue for identifying clients. Advantages of this approach were that the CSC could identify clients who were articulate and represented a wide range of support needs. Potential disadvantages were that we may have not gained access to clients who were dissatisfied with the service, or who were particularly challenging clients. Kazi (2000) noted that a limitation of both pragmatist and interpretivist approaches in social work research is too much emphasis being placed on the needs of stakeholders with the result that findings are neither broad nor holistic enough to capture the broader picture. We attempted to mitigate the risk of narrow 
vision by recruiting a more diverse sample of referrers in the region and by recruiting a senior member of the local regional district council. The demographic profile of client participants is described in Table 1.

\section{Data collection}

Separate interview schedules were developed for client and informant groups. The former contained open-ended questions exploring clients' connection with the community, their needs, and the support available to them. The latter focused on the issues pertinent to referrers and the challenges referrers faced in their roles. Both interview schedules included questions on ageing in place in this particular rural community, the impact of the CSC position on older residents of Central Otago, and what gaps remained in the provision of aged support in rural areas.

All participants gave their informed consent prior to their inclusion in the study. Interviews with clients were conducted in the homes of the older rural residents, while the key informant interviews were conducted in the respective workplaces. The CSC introduced the first author to the client participant in their home and then left prior to the interview to ensure confidentiality. All client participants were offered the opportunity to have a support person present, and one participant's daughter chose to be present. Koha in the form of a store-bought cake was offered to client participants on the day of the interview to show thanks for participating in the project. All interviews were recorded and transcribed.

\section{Data analysis}

Our analytical framework was an adapted template organising style (Crabtree \& Miller, 1999) that was oriented around the project objectives and the primary thematics from relevant literature on rural ageing in Aotearoa New Zealand and Australia. These included: issues facing older members of the Central
Table 1. Client Participant Demographics

\begin{tabular}{|c|c|}
\hline 1. Age Range & $\begin{array}{l}\text { Number of } \\
\text { Participants }\end{array}$ \\
\hline $70-75$ & 2 \\
\hline $75-80$ & 1 \\
\hline $80-85$ & 1 \\
\hline $85-90$ & 1 \\
\hline $90-95$ & 1 \\
\hline \multicolumn{2}{|l|}{ 2. Gender } \\
\hline Male & 4 (or 67\%) \\
\hline Female & 2 (or 33\%) \\
\hline \multicolumn{2}{|l|}{ 3. Self-reported ethnicity } \\
\hline NZ/ European & 5 \\
\hline NZ/ Māori & 1 \\
\hline Other & 0 \\
\hline \multicolumn{2}{|l|}{ 4. Housing tenure } \\
\hline Own their own home & 4 \\
\hline Rental & 2 \\
\hline Living independently & 6 \\
\hline \multicolumn{2}{|l|}{ 5. Marital status } \\
\hline Single & 3 \\
\hline Married & 1 \\
\hline Widowed & 2 \\
\hline \multicolumn{2}{|l|}{ 6. Driving status } \\
\hline Driving & 1 \\
\hline Driving but limited to $<80 \mathrm{~km}$ & 3 \\
\hline Recently not driving & 1 \\
\hline Not driving & 1 \\
\hline \multicolumn{2}{|l|}{ 7. Health status* } \\
\hline Good & 2 \\
\hline Fair to limited & 4 \\
\hline Poor & 0 \\
\hline Awaiting or undergoing treatment & 3 \\
\hline \multicolumn{2}{|l|}{ 8. Additional support } \\
\hline Family & 3 \\
\hline Social group & 2 \\
\hline Church & 2 \\
\hline NGO/ DHB & 6 \\
\hline
\end{tabular}

Otago community (mobility, transport, service availability and access to services, affordability and poverty, accommodation, isolation (Lidgard, 2006)); the impact of the CSC position; and what gaps remain. 
The analysis of the data followed a general inductive approach (Thomas, 2006).

This study was approved by the University of Otago Human Ethics Committee (Ref. D19-262). Additionally, the Ngāi Tahu Research Consultation Committee offered guidance on cultural competency and care of older people during the interviewing process.

\section{Findings}

Two major themes emerged from this research: (1) ageing in Central Otago; and (2) providing aged social support in Central Otago.

\section{Ageing in Central Otago}

Social identity and community. Being a resident of Central Otago was an important aspect of identity for all CSC client participants. Participants described a strong sense of community and interconnectedness within their communities. A senior member of council said, "in these small towns people still care about you." Participants all referred to the importance of membership in organisations such as churches, networks and clubs, friendship groups or familial support. One male client participant noted that, "once you have made a connection it is lifelong" in reference to participation in local social clubs. Similarly, the CSC commented that, "when the connection with the client and associated networks are strong then everything else works around that. The informal networks are extremely important." Smith (2013, p. 17) identified this importance of belonging and participation as a strong value of rural communities. However, the closeness of these networks can create a barrier for outreach because of the potential for gossip and judgement. An Alexandra-based social worker noted:

The downside of living in small communities is the stigma associated with needing help. People tend to avoid seeking help because they don't want assumptions to be made about them. (Social worker C)

Although most participants had family living locally, they also indicated that they could not necessarily rely upon them or were reluctant to request familial support. This might have been because they did not want to be judged as incompetent or become a burden to their families.

Isolation and loneliness. Declines in health and/or mobility issues can have an enormous impact on social participation, with social isolation being identified as a health issue facing many older people (Lilburn, 2016; Nicholson, 2012; Shankar, McMunn, Banks, \& Steptoe, 2011; WrightSt Clair, Neville, Forsyth, White, \& Napier, 2017). This was also identified by many participants as a major issue in Central Otago. One male client said, "then all of a sudden you can't walk. [...] You're old."

One male client noted that "the biggest drawback is living alone." Loneliness and isolation was an issue for many older community members according to key informants: "older folks feel as though they are doing it alone" (Social worker B). However, a senior member of the local council asked, "how are the services supposed to find people who isolate themselves?" This reflects that few older people self-refer to support services and speaks to a tension between respecting the privacy of community members, but also recognising the transition from independence and keeping to oneself into isolation and loneliness and reluctance to reach out or to let others in. It may also reflect that services are not connecting with potential service users: "I used to like going to work and buying things for myself. I do have my own independence but it's getting smaller [...] Because I'm getting old" (male client). One female client participant described struggling to care for her disabled husband:

Oh, it was awful. I was so exhausted, I went to sleep. Must have gone to sleep, and he 
must have got out of bed, fell out of bed and had a turn, and he must have crawled into here, and he couldn't get up. He was calling me, "Help" [...] They just took him to the hospital and that was the end.

Housing and poverty. In this region, the costs of living can be high compared to large urban centres because of haulage costs for fuel and foodstuffs. While a winter electricity subsidy is available to those aged 65 and over, the severity of winters in Central Otago combined with high costs of electricity, gas, and firewood places additional pressure on limited incomes. A compounding factor is that older housing stock in Central Otago (as elsewhere in Aotearoa New Zealand) is damp and cold, and this also has a negative impact on the health of inhabitants (Howden-Chapman et al., 2012). The strong economic growth in Central Otago over the previous decade has created enormous pressure on local accommodation. Mirroring national trends, house prices in Central Otago have trebled over the previous 15 years with regional rates increasing apace, and housing affordability has become a major issue for all residents with limited incomes (Johnson, Howden-Chapman, \& Eaqub, 2018; Southern District Health Board, 2019). The local council's attempts to interest developers in social housing programmes (Jones, 2017) have not yet been successful, and the council appeared ambivalent about its role in the provision of housing and which demographic (young or older adults) should be prioritised. Thus, the cost of accommodation was a key factor in the financial hardship described by all participants. For those renting, this was the cost of rents, while for homeowners, the escalating house prices in the region have been matched in increasing rates. Even if mortgage-free, homeowners have insurance and maintenance costs:

We're extremely expensive here for accommodation ... and there is a lot of people that are in the private rental area. [The CSC] had a situation a couple of weeks ago, where she became aware of an elderly gentleman out in [another town] that was having to shift house. I don't know if he was being evicted or not. She, through the local real estate again, found him a house to rent, and it sounds like an old bach-type thing. Won't be insulated. (Social worker B)

One participant commented on the lack of suitable housing, criticising limited planning for the ageing population in his community:

I'd like to sell this [house] and go into a pensioner estate. I missed out this time [...] because there's heaps of people downsizing. I think they should build a lot more downsized houses for older people [...] It's not like the population who is ageing here has just turned up. They've always been here. They've [council] had time to plan for it but they just didn't and now it's a shortage. (Male client)

One major component of the CSC role was assisting clients in managing their finances. All client participants described having to be careful with their income. One male client participant told us: "I've finished up with no money due to one or two bad schemes. So basically my total income is a pension." While several client participants had state-funded home services such as cleaning and gardening, they described struggling to pay for health-related costs such as hearing aids. Participants often were unaware of what financial assistance was available. One female client described how the CSC arranged for her to receive several allowances that she was unaware of and did not know she was eligible for.

\section{Providing aged social support in Central Otago}

Service visibility. While local health professionals were aware of the ACO CSC service, it appeared to have a relatively low profile within the community:

Healthcare is the biggest referral agency for clients who require needs assessment 
at home, or for someone who is not coping etc. but because she [CSC] has been in the community for a long time ... It's a lot of word of mouth. (Social worker B)

Despite the co-location of three agencies servicing the older population within a community centre, client participants had all been unaware of the availability of community social work services prior to their referral to the ACO CSC. One male client participant who had lived in the Central Otago community for nearly 20 years noted: "I think that it [social work services] probably needs more publicity that it's available. I'm not even sure with my connections that I would have found it." The relatively low profile of aged services was acknowledged by key informants. Support services (including social work services) were "silent agencies. There is still a limitation to our presence in the community and people not realising that we are here" (Social worker B). One reason for this might be the relative invisibility of older people in the community (Walker, Weare, \& Tully, 2018). In addition, client participants' lack of mobility may result in not noticing the ACO services because they are not frequenting the community centre that hosts these services.

Meeting client need. As noted, the current CSC position is part time (0.5FTE). Being a highly mobile position means that the CSC can spend a significant amount of time (up to one hour) travelling to meet clients at the outer boundaries of her geographical jurisdiction. The CSC described struggling to meet the increasing demand for her services and the concomitant increase in caseload: "I visited 23 clients in November. Twelve of these were new referrals. Others were welfare or follow ups" (CSC). Ideally, the CSC would refer clients to other service and care providers once the acute issue or crisis has been managed, but this was not always possible because of broader service gaps in the region. ACO clients frequently have multiple and compounding problems and cannot rely on other forms of community or familial support.

It is one thing to provide a good supportive service to the client in need and then hand over or leave the client to their current independence. But the reality is, you respond with a purpose for your visit but then you build rapport and ensure they feel safe and supported, through this, they open up and you begin to learn all of the other difficulties that they have. You feel obligated because no one else was aware (or told). It may be as simple as you just knowing the kind of help they need or who it is that they need to speak to, so they remain on your client list because they have no one else. (CSC)

The referrers and other social workers interviewed commented on the broad scopes of social work positions and the undefined boundaries of rural social work in general. In addition to time spent travelling and with clients, much of the CSC's work involved navigating the bureaucracies and administrations of government agencies and departments (particularly Social Development (MSD), Work and Income (WINZ), and Inland Revenue (IRD)) on behalf of clients. She also spent many hours searching local websites and newspapers for accommodation for clients.

[It's] the "one stop shop" nature of this position; the benefits are that you can see everything that is happening and needs which haven't been uncovered. However, it's very reactive; there is either not lot of work, and time would be spent doing prevention programmes or setting clients up with appropriate networks, or being swamped with no time to react or apply preventive procedures and instead the quality of care is reduced. (Social worker D)

Clients of the ACO service all spoke of the positive impact that the CSC had on their lives. The CSC was frequently described as 
a problem-solving friend who filled social as well as service coordination needs:

It's really just all of the talking. Talking about money and issues and everything about me. If I need something, she goes around and talks to people and comes along with me. She drives me because I can't drive far. She just holds your hand all the way through. (Female client)

Another client participant said "it's good to know the support is there both as a friend and as a specialist person. She'd be the first person I rang if I had a problem. She picked up that I was getting depressed."

The social work participants commented that the high demand for support services meant that social workers in Central Otago tended to work in a reactive way attempting to address escalating problems for clients instead of setting up community programmes and interventions that would facilitate identification of and planning for looming crisis points ahead of an actual crisis.

The lack of long-term community care services to refer clients to resulted in the CSC working well beyond the usual scopes of social work roles (such as driving clients to church). This was viewed as an inevitable component of the rural scope of practice. Social work participants noted that one risk of such close support is that clients might become inappropriately dependent on their social worker:

Where your initial position is specific but within a few visits you become their most trustworthy contact and support and so, anything they need after that, you are organising, contributing, assessing, and evaluating. (Social worker D)

The danger then, as another key informant noted was that, "support outside of the social work role can become detrimental for the client if you then pull back on your support" (Social worker B).
Cohesion and integration among local service providers. The CSC had wellestablished professional networks, particularly with the social workers in adjacent jurisdictions and with other agencies in the region. Interestingly, just prior to our fieldwork, a new NGO had secured local funding and begun operating in the region providing networking and resources to older community members. Social worker participants acknowledged that there was room for other operators given the degree of unmet need, but also expressed concerns about the impact that another competitor for scant funding resources might have on existing services, and the degree to which the new operator would link in with them. This pointed toward the potential for fragmentation of services. Improved communication and linking between service providers was considered by social worker participants to be critical for improving client outcomes and improving workloads for social workers in Central Otago:

The effectiveness [of services] depends on the different agencies working together in sharing information, like an agency hub. We have to know who is in our areas. Other agencies need to help [...] For the community connectivity and social/ carer initiatives to work there needs to be more engagement from all of the agencies, there is still a sense of each agency working independently, resulting in [local] initiatives not reaching the wider Central Otago. (Social worker B)

Government departments and their local agencies were heavily criticised by social worker participants for poor integration and cohesion of services, and for not being userfriendly for an older cohort (by expecting them to conduct business by telephone or internet). This also encompassed poor communication and slow responses.

[The CSC] would help clients with various applications over the course of a week, then a week later the application 
will be processed. The client can be waiting 2-3 weeks (after an event) for a response. (Social worker $\mathrm{B}$ )

Older people can find it very difficult to deal with centralised services because they frequently do not have internet connectivity (and quality of connectivity continues to be an issue in many rural areas), or the skills to access online services (Citizens Advice Bureaux, 2020) although numbers of older people using the internet are relatively high in Aotearoa New Zealand (Koopman-Boyden \& Reid, 2009)), and can struggle with navigating helplines because of deafness. Of the six client participants, although some had a smart cellphone, none had access to a computer. One participant offered the solution of navigators within government departments to prioritise and assist older adults.

Within a service (e.g., MSD), it would be ideal to have a department or personal for clients over $65 \mathrm{yrs}$, or someone specifically for your district. (Social worker B)

Building a higher profile in the community was identified as another strategy that would improve the visibility of ACO social workers and their outreach:

There is still a limitation to our presence in the community and people not realising that we are here, and that we are amongst all of the other agencies-a community house. We could be working from home, it makes no difference. (Social worker B)

One suggestion was that a central hub or drop-in centre for older people (as the ACO hub in the regional urban centre has) would provide an opportunity for socialising, and for the agencies providing services to gain improved knowledge of the older people at risk in the community through the networking that such a hub would facilitate.

Ideally, community volunteers would be able to take over cases referred by CSC, and work with government agencies on behalf of older people.

[There is a] lack of carers/volunteers and potentially still a large gap in healthcare entitlements; not knowing what you're entitled to or how to apply for more. (Social worker D)

With less acute work and a manageable caseload, the CSC would be able to work with volunteer programmes to assist with meeting the needs of older community members.

\section{Discussion}

Participants in this study indicated that, within Central Otago, increasing housing unaffordability, accommodation insecurity, mobility and transport issues, and financial precarity characterise life for many older people. This precarity drives a significant need for community support, and the current 0.5 FTE ACO CSC position is struggling to cope with the demand for aged social work services. While changing the infrastructural issues (health service accessibility, transport and accommodation) identified by participants is well beyond the scope of this project, suggestions for more effective support to older residents of the region include increased FTEs for specialised aged social work, and better coordination within and between government and NGO agencies in the community aged support spaces.

The Ministry of Social Development has recently updated the "Live Stronger, for Longer" policy with the 2019 "Better Later Life" policy (Office for Seniors, 2019). This document, like many other governmental policies, although age-specific, does not extend to rurality, nor does it specify the resources and specialised support professionals and social workers required for the implementation of such action points. We suggest that there remains a substantial disconnect between the government commitment to supporting older rural residents and aged-social-work in this rural 
community and it is this space in which nonprofit and non-government organisations such as ACO operate. Their ability to make a difference is dependent on short-term funding and this makes future planning very difficult.

Aldrich (2010) noted that NGO social work positions are generally not well-resourced compared to government positions; however, there are benefits (Smith, 2013). Government-funded social work positions have prescriptive scopes of practice that result in top-down social support which make it difficult to meet a rural community's needs. NGO social work positions can be more responsive to community needs because they have less rigidly defined role descriptions and their practice is bottom-up (Smith, 2013).

The rural context is what makes social work unique in rural communities (Smith, 2013). Because rural social workers are also members of the communities they serve, they are likely to encounter clients and potential clients at local social events and gatherings (Pugh, 2007). This community connectedness makes the boundaries between personal and professional lives less defined in rural social work than they might be in urban social work (Brand \& Kesting, 1999; Green, 2003; Pugh, 2007). Taking a client to church is a good illustration of this. Pugh (2007) commented on the "urbanism" that infuses formal social work practice and policy on boundary setting, yet this is impractical in rural social work. The maintenance of formal professional boundaries (a neutral and detached stance towards the client) can impede relationship-building and the development of trust (O'Leary, Tsui, \& Ruch, 2013; Pugh, 2007). O'Leary et al. (2013) suggest that a more authentic model of boundaries in social work should promote connection (within ethical parameters) rather than professional distance and separation. The social support relationships described by both the CSC and her clients provide examples of this model. These relationships were characterised by high degrees of trust, respect, safety, dignity, kindness and compassion. Hirst (2019) argued that one potential risk of blurred boundaries is burnout. Managing burnout before it occurs is one benefit of professional supervision in social work and of peer support (Hirst, 2019). Ideally, social workers in rural areas would provide strong peer support to each other, beyond government and NGO boundaries of their jurisdictions.

Aldrich (2010) argued there is a growing need for dedicated specialist social workers to service older people within communities. The value of specialist social workers for older people lies partly in the practical scope of their practice. According to Foster and Beddoe (2012), this includes managing cases of elder abuse and assisting older people in dealing with issues of grief and loss. These specialist roles can coordinate healthcare and services for older people and assist with transitions between primary and secondary care. Another key value lies in the social worker's ability to challenge ageism through advocacy and education (Aldrich, 2010). This includes improving the visibility and value of older people within their communities, thus empowering older community members (Lloyd \& Sullivan, 2018).

Effective social work for older people also requires a unique skillset that is underpinned by strength-based models of practice (Aldrich, 2010; Foster \& Beddoe, 2012). This includes an eclectic knowledge base with an understanding of mental health and psychosocial issues in older adults, and family issues (Aldrich, 2010). Familiarity with healthcare and welfare systems and processes, as well as financial and legal structures and provision of public and private supports is also necessary (Aldrich, 2010). Core competencies include the ability to organise and mobilise community support and strengthen community networks. Foster and Beddoe (2012) identified communication and facilitation skills as requisite. A thorough knowledge of the community, its character and traditions are essential for those working in rural areas (Pugh, 2007). The scope and 
competencies of the ACO CSC role in Central Otago appeared to be well aligned with these values and specialised skillsets. Pugh (2007) notes that another core competency in the Aotearoa New Zealand social work setting is cultural sensitivity. The social and health disadvantage that older Māori have experienced during their lifetime persists into old age (Teh et al., 2014). Aldrich (2010) noted that the "Positive Ageing Strategy" (2001) affirmed Māori values in future policy and committed to strengthening capability in older Māori and including whānau in decision making. The structural violence inherent within government institutions and organisations means that older Māori adults may be distrustful of government agencies (Aldrich, 2010). This is a strong rationale for the provision of Māori specialist social work services for older Māori.

The concept of precarity is relevant. It has traditionally been defined in terms of employment and income insecurity and is used recently to refer to the trajectory of growing old (Grenier et al., 2017; Grenier, Phillipson, \& Settersten, 2020), which is characterised by risk, vulnerability, uncertainty and instability (Grenier et al., 2017; Groot et al., 2017; McCormack \& Salmenniemi, 2016). Precarity is apparent at several levels in our research. At the micro level, many older people in Central Otago are living precariously because of financial and housing insecurity (Southern District Health Board, 2019). Health status for older individuals can be highly precarious because relatively minor losses in function can result in significant health deficits and loneliness (Settersten, 2020). The relative invisibility of older people has been well documented (Mordini \& de Hurt, 2010; Office for Seniors, 2016; Williams, 2007), and the low social and economic value of aged care work has been attributed to the low social value of older people (NZ Labour Party, Green Party of Aotearoa NZ \& Grey Power NZ, 2010). Fine (2020) described the public invisibility of care services for older people as another form of precarity. It is tempting to suggest that the public invisibility of the Central
Otago ACO services for older people reflects this phenomenon. At the meso level, the operation of NGOs is precarious because the delivery of services is dependent upon securing sustainable funding. This, in turn, results in precarious, insecure short-term and part-time support positions. Such employment conditions combined with the demands of escalating caseloads can lead to burnout in professionals (Hirst, 2019). While there is strong demand for additional frontline support in Central Otago, an increase in service providers may lead to increased competition for the limited available funding and fragmentation of service delivery. Macro level precarity is evident in the competing priorities of local regional district councils regarding decisions about where to place limited resources. This means that opportunities to grow business and rates revenue in rural communities may take precedence over providing services for older people.

Initiatives have been taken by some urban district councils to create age-friendly communities (SuperSeniors, 2020). Priorities for these initiatives include addressing the built environment and outdoor spaces, transportation, housing, social participation, respect and social inclusion, civic participation and employment, community support and health services. These priorities are all applicable to the small rural communities of Central Otago. Successful age-friendly community interventions have the potential to mitigate some sources of precarity for older rural people yet require long-term commitment of financial resource by both central and local governments. Without it, the ability for rural older people to not only age in place in their own communities, but for these communities to be a good place to grow old (Keating, 2008) may continue to be a precarious ambition.

\section{Conclusion}

Availability of, and access to, health and government services, combined with distance, mobility issues, accommodation 
insecurity, and poverty provide challenges for those ageing in a rural community. As the population ages in Central Otago, the proportion of older people living precariously in this community is likely to escalate, along with demand for specialist aged social workers. Our research indicates that social workers such as the ACO CSC have a strong positive impact on older people's wellbeing in this region, yet such positions are themselves precarious. A strong case exists for establishing specialist aged social work services in rural areas. However, effective support to older rural people also requires coordination within and between government and NGO agencies in the community aged support space.

\section{Acknowledgements}

This research was supported by an Otago Medical Research Foundation-Aotearoa New Zealand Private Summer Scholarship, and by the Rural Aotearoa Research Network, established through the 2017 Research Development Investment Award from Health Research South, Otago Medical School, and University of Otago. We are particularly grateful to the support provided by Age Concern Otago and the University of Otago CARE Research Theme. We would like to thank all participants for their generosity in agreeing to take part.

Accepted 16 October 2020

Published 15 December 2020

\section{References}

Aldrich, R. (2010). The ageing demographic transition: The impact on elderly and social workers. Aotearoa New Zealand Social Work, 22(2), 4-12.

Anastas, J. (2004). Quality in qualitative evaluation: Issues and possible answers. Research on Social Work Practice, 14(1), 57-65.

Anderson, C. (2010). Presenting and evaluating qualitative research. American Journal of Pharmaceutical Education, 74(8), 141. doi:10.5688/aj7408141

Associate Minister of Health. (2016). Healthy ageing strategy. Ministry of Health. Retrieved from https://www.health. govt.nz/system/files/documents/ publications/healthy-ageing-strategy_june_2017.pdf
Brand, J., \& Kesting, A. (1999). Sharing the space and blurring the boundaries. In L. Briskman \& M. Lynn (Eds.), Challenging rural practice (pp. 162-171). Deakin University Press.

Braun, V., \& Clarke, V. (2013). Successful qualitative research: A practical guide for beginners. Sage.

Chalmers, A. I., \& Joseph, A. E. (1998). Rural change and the elderly in rural places: Commentaries from New Zealand. Journal of Rural Studies, 14(2), 155-165. doi:10.1016/S0743-0167(97)00050-8

Citizens Advice Bureaux. (2020). Face-to-face and Digital Exclusion. Citizens Advice Bureaux New Zealand.

Crabtree, B. F., \& Miller, W. L. (1999). Using codes and code manuals: A template organising style of interpretation. In B. F. Crabtreee, \& W. L. Miller (Eds.), Doing qualitative research (pp.163-177). Sage Publications.

Davey, J. (2006). "Ageing in place": The views of older homeowners on maintenance, renovation and adaptation. Social Policy Journal of New Zealand, 27, 128-141.

Dobl, S., Beddoe, L., \& Huggard, P. (2017). Primary health care social work in Aotearoa New Zealand: An exploratory investigation. Aotearoa New Zealand Social Work, 29(2), 119-130.

Dobl, S., \& Ross, A. (2013). Thinking beyond the contract: A journey to collaborative community social work. Aotearoa New Zealand Social Work, 25(1), 43-53.

Ergler, C. R., Lovell, S., Watkins, A., Milligan, C., Thompson, L., Exeter, D. J., \& Kearns, R. J. (2017). Looking back and moving forward: Health geography in Aotearoa and beyond. New Zealand Geographer, 73(3), 205-217.

Fearnley, D., Lawrenson, R., \& Nixon, G. (2016). "Poorly defined": Unknown unknowns in New Zealand rural health. The New Zealand Medical Journal (Online), 129(1439), 77.

Fine, M. (2020). Reconstructing dependency: Precarity, precariousness and care in old age. In A. Grenier, C. Phillipson, \& R. Settersten Jr (Eds.), Precarity and ageing: Understanding insecurity and risk in later life (pp. 169-189). Policy Press.

Flick, U. (2018). Triangulation in data collection. In U. Flick (Ed.), The Sage handbook of qualitative data collection (pp. 527-544). Sage.

Foster, S., \& Beddoe, L. (2012). Social work with older adults in primary health: Is it time to move our focus? Aotearoa New Zealand Social Work, 24(2), 37-48.

Green, R. (2003). Social work in rural areas: A personal and professional challenge. Australian Social Work, 56(3), 209-219.

Grenier, A., Phillipson, C., Rudmand, D., Hatzifilalithisa, S., Kobayashie K., \& Marierf, P. (2017). Precarity in late life: Understanding new forms of risk and insecurity. Journal of Ageing Studies 43, 9-14.

Grenier, A., Phillipson, C., \& Settersten, R. A. J. (Eds.). (2020). Precarity and ageing: Understanding insecurity and risk in later life. Policy Press.

Groot, S., van Ommen, C., Masters-Awatere, B., \& TassellMatamua, N. (Eds). (2017). Precarity: Uncertain, insecure and unequal lives in Aotearoa New Zealand. Massey University Press. 
Hirst, V. (2019). Burnout in social work: The supervisor's role. Aotearoa New Zealand Social Work Journal, 31(3), 122-126.

Hiscock, R., Pearce, J., Blakely, T., \& Witten, K. (2008). Is neighborhood access to health care provision associated with individual-level utilization and satisfaction? Health Services Research, 43(6), 2183-2200.

Howard-Brown, C. (2018). Working towards primary care and aged residential care integration (Unpublished doctoral thesis). University of Otago, Dunedin, NZ.

Howden-Chapman, P., Viggers, H., Chapman, R., O'Sullivan, K., Telfar Barnard, L., \& Lloyd, B. (2012). Tackling cold housing and fuel poverty in New Zealand: A review of policies, research, and health impacts. Energy Policy, 49, 134-142.

Johnson, A., Howden-Chapman, P., \& Eaqub, S. (2018). A stocktake of New Zealand's housing February 2018. Retrieved from https://www.beehive.govt.nz/sites/default/ files/2018-02/A\%20Stocktake\%20Of\%20New\%20 Zealand\%27s\%20Housing.pdf

Jones, P. (2017, 12 May). Trust could help-Mayor. Otago Daily Times. Retrieved from https://www. odt.co.nz/regions/central-otago/trust-could-help$\%$ E2\%80\%94mayor

Kazi, M. A. F. (2000). Contemporary perspectives in the evaluation of practice. British Journal of Social Work, 30 755-768.

Keating, N. (2008). Rural ageing: A good place to grow old? Policy Press.

Keating, N., \& Phillips, J. (2008). A critical human ecology perspective on rural ageing. In Keating (Ed.), Rural ageing: A good place to grow old? (pp. 1-10). Policy Press.

Koopman-Boyden, P. G., \& Reid, S. L. (2009). Internet/e-mail usage and well-being among 65-84 year olds in New Zealand: Policy implications. Educational Gerontology, 35(11), 990-1007.

Lidgard, J. (2006). Ageing in rural areas: A review of the literature. Retrieved from http://www.ewas.net.nz/ Publications/filesEWAS/Rural\%20ageing.pdf

Lilburn, L. (2016). Ageing in place and social isolation in rural dwelling older adults (master's thesis). Massey University, NZ.

Lloyd, L., \& Sullivan, M. P. (2018). Ageing, ethics and social welfare: Contemporary social work and social care practices with older people. Ethics and Social Welfare, 12(3), 201-203.

Malatsky, C., \& Bourke, L. (2016). Re-producing rural health: Challenging dominant discourses and the manifestation of power. Journal of Rural Studies, 45 157-164.

McCormack, D., \& Salmenniemi, S. (2016). The biopolitics of precarity and the self. European Journal of Cultural Studies 19(1), 3-15.

Ministry of Health. (2001). New Zealand postive ageing strategy. Retrieved from https://www.msd.govt.nz/aboutmsd-and-our-work/publications-resources/planningstrategy/positive-ageing/

Ministry of Health. (2011). Health of older people. Retrieved from https://www.health.govt.nz/our-work life-stages/health-older-people?mega=Our\%20 work\&title=Health\%20of\%20older\%20people.
Mordini, E., \& de Hert, P. (Eds.). (2010). Ageing and invisibility (Vol. 7). IOS Press.

Morgan, D. L. (2007). Paradigms lost and pragmatism regained: Methodological implications of combining qualitative and quantitative methods. Journal of Mixed Methods Research, 1(1), 48-76.

National Health Committee. (2010). Rural health: Challenges of distance, opportunities for innovation. Ministry of Health. Retrieved from https://www.moh.govt.nz/ notebook/nbbooks.nsf/0/A06B332FA631554BCC2576C0 0008CE96/\$file/rural-health-challenges-opportunities.pdf

Nicholson, N. R. (2012). A review of social isolation: an important but underassessed condition in older adults The Journal of Primary Prevention, 33(2-3), 137-152.

Nixon, G., Samaranayaka, A., de Graaf, B., McKechnie, R., Blattner, K., \& Dovey, S. (2014). Geographic disparities in the utilisation of computed tomography scanning services in southern New Zealand. Health Policy, 118, 222-228.

NZ Labour Party, Green Party of Aotearoa NZ, \& Grey Power NZ. (2010). A report into aged care: What does the future hold for older New Zealanders? Retrieved from https://www.mentalhealth.org.nz/assets/Dig-deeper/Areport-into-Aged-care.pdf

Office for Seniors. (2016). Attitudes towards ageing. Ministry of Social Development. Retrieved from http://www. superseniors.msd.govt.nz/documents/attitudes-towardsageing-research/attitudes-toward-ageing-summaryreport-2016.pdf

Office for Seniors. (2019). Better later life; he oranga kaumātua 2019 to 2034. Retrieved from http://www. superseniors.msd.govt.nz/documents/better-later-life/ better-later-life-strategy.pdf

O'Leary, P., Tsui, M. S., \& Ruch, G. (2013). The boundaries of the social work relationship revisited: Towards a connected, inclusive and dynamic conceptualisation. British Journal of Social Work, 43(1), 135-153.

Parr, H., \& Philo, C. (2003). Rural mental health and social geographies of caring. Social and Cultural Geography, 4(4), 471-488.

Parsons, M., Senior, H. E. J., Kerse, N., Chen, M.-h., Jacobs, S., Vanderhoorn, S., . . A Anderson, C. (2012). The assessment of services promoting independence and recovery in elders trial (ASPIRE): A pre-planned metaanalysis of three independent randomised controlled trial evaluations of ageing in place initiatives in New Zealand. Age and Ageing, 41(6), 722-728. doi:10.1093/ageing/ afs 113

Pittaway, M. (2017, July). Accessing rural health services: Rural realities: Rural women in New Zealand. Department of Public Health Seminar, University of Otago, Wellington.

Pomeroy, A., \& Newell, J. (2011). Rural community resilience and climate change. A report to the Ministry of Agriculture and Forestry, New Zealand. University of Otago.

Pugh, R. (2007). Dual relationships: Personal and professional boundaries in rural social work. British Journal of Social Work, 37(8), 1405-1423.

Rural Expert Advisory Group. (2002). Implementing the Primary Health Care Strategy in rural New Zealand. Ministry of Health. Retrieved from https:// www.moh.govt.nz/notebook/nbbooks.nsf/0/5e 56a47c1768d27ecc256c190076e807/\$FILE/ RuralPrimaryHealthStrategylmplementation.pdf 
Scharf, T., \& Bartlam, B. (2008). Ageing and social exclusion in rural communities. In N. Keating (Ed.), Rural ageing: A good place to grow old? (pp. 97-108). Policy Press.

Schwandt, T. A. (1998). Constructivist, interpretivist approaches to human inquiry. In N. K. Denzin \& Y. S. Lincoln (Eds.), The landscape of qualitative research: Theories and issues (pp. 221-259). Sage.

Settersten, R., Jr. (2020). How life course dynamics matter for precarity in later life. In A. Grenier, C. Phillipson, \& R. Settersten Jr. (Eds.), Precarity and ageing: Understanding insecurity and risk in later life (pp. 19-40). Policy Press.

Shankar, A., McMunn, A., Banks, J., \& Steptoe, A. (2011). Loneliness, social isolation, and behavioral and biological health indicators in older adults. Health Psychology, 30(4), 377-385.

Smith, K., Humphreys, J., \& Wilson, M. (2008). Addressing the health disadvantage of rural populations: how does epidemiological evidence inform rural health policies and research? Australian Journal of Rural Health, 16(2), 56-66.

Smith, P. (2013). Whose culture is it anyway? Social working within a rural community. Aotearoa New Zealand Social Work, 25(1), 14-23.

Southern District Health Board. (2019). Draft report: Pēhea tou Kāinga. How's your home? Central Otago housing: The human story. Retrieved from https://www. southernhealth.nz/sites/default/files/2019-09/SDHB\%20 CODC $\% 2$ Housing\%20report\%20\%20-\%20\%2020\%20 Sept\%202019.pdf

Statistics New Zealand. (2020a). Population. Retrieved from https://www.stats.govt.nz/topics/population

Statistics New Zealand. (2020b). Central Otago District. Retrieved from https://www.stats.govt.nz/tools/2018census-place-summaries/central-otago-district

SuperSeniors. (2020). Age-friendly communities. Retrieved from http://www.superseniors.msd.govt.nz/about-superseniors/ office-for-seniors/age-friendly-communities.html

Teh, R., Kerse, N., Kepa, M., Doughty, R. N., Moyes, S., Wiles, J., ... \& Mace, C. (2014). Self-rated health, healthrelated behaviours and medical conditions of Maori and non-Maori in advanced age: LiLACS NZ. The New Zealand Medical Journal (Online), 127(1397).

Thomas, D. R. (2006). A general inductive approach for analyzing qualitative evaluation data. American Journal of Evaluation, 27(2), 237-246.

Walkner, T. J. , Weare, A. M. , \& Tully, M. (2018). "You get old. You get invisible": Social isolation and the challenge of communicating with aging women. Journal of Women and Aging, 30(5), 399-416.

Wenger, C., \& Keating, N. (2008). The evolution of networks of older rural adults. In N. Keating (Ed.), Rural ageing: $A$ good place to grow old? (pp. 33-42). Policy Press.

Wiles, J. L., Leibing, A., Guberman, N., Reeve, J., \& Allen, R. E. (2012). The meaning of "aging in place" to older people. The Gerontologist, 52(3), 357-366.

Williams, M. (2007). Invisible, unequal, and forgotten: Health disparities in the elderly. Notre Dame Journal of Ethics \& Pubic Policy, 21, 441-478.

Wright-St Clair, V., Neville, S., Forsyth, V., White, L., \& Napier, S. (2017). Integrative review of older adult Ioneliness and social isolation in Aotearoa/New Zealand. Australasian Journal on Ageing, 36(2), 114-123. 